\title{
Fuentes para la historia de la Iglesia en el Centro Documental de la Memoria Histórica
}

\author{
Sources for Church History in the Historical \\ Memory Documentary Center
}

José Luis HERNÁNDEZ LUIS

Técnico superior de archivos

joluherlu@yahoo.es

\begin{abstract}
The Historical Memory Documentary Center preserves various documentary collections of interest for the history of the Catholic Church in contemporary Spain. Among these, the following collections stand out: the Causa General, of special relevance for the study of anti-religious violence during the Second Republic and the Spanish Civil War; several photographic archives that reveal the widespread damage suffered by Spain's cultural heritage immediately after the conflict, and numerous works on anticlerical controversy that the investigator will find in the specialized library.
\end{abstract}

Keywords: Sources, history, Catholic Church, Spain, 2oth Century.
Resumen: El Centro Documental de la Memoria Histórica conserva diversos conjuntos documentales de interés para la historia de la Iglesia Católica en la España contemporánea. Entre ellos destacan la Causa General, de especial relevancia para el estudio de la violencia antirreligiosa durante la Segunda República y la Guerra Civil; varios archivos fotográficos que revelan los múltiples daños que sufrió el patrimonio cultural a raíz del conflicto y las numerosas obras de controversia anticlerical que encontrará el investigador en la biblioteca especializada.

Palabras clave: Fuentes, historia, Iglesia, España, siglo Xx.

\section{INTRODUCCIÓN}

El origen del Centro Documental de la Memoria Histórica (CDMH) se remonta a la Guerra Civil Española (1936-1939)․․ Aunque prácticamente desde los primeros compases del conflicto ambos bandos en litigio utilizarán documentos incautados

1 El CDMH se encuentra en la c/ Gibraltar, 2, 37008-Salamanca. Información completa sobre el Centro en <www.mecd.gob.es/cultura-mecd/areas-cultura/archivos/mc/archivos/cdmh/portada. html> [consultado 27/10/2016]. 
para perseguir al adversario, será a partir de la primavera de 1937 cuando los franquistas organicen de manera sistemática la requisa de documentación republicana que emplearán con fines propagandísticos y represivos hasta el ocaso del régimen². Durante la Transición a la Democracia el antiguo organismo pseudopolicial creado por el franquismo en Salamanca se convirtió en un establecimiento abierto a los investigadores, la Sección Guerra Civil del Archivo Histórico Nacional ${ }^{3}$, que ascendió de categoría administrativa apenas dos décadas más tarde como Archivo General de la Guerra Civil Española ${ }^{4}$. Pocos años después, al socaire de la recuperación de la memoria histórica, el establecimiento ha experimentado notables cambios. Por ministerio de la Ley 21/2005 el Archivo se ha integrado en el Centro Documental de la Memoria Histórica ${ }^{5}$, un organismo de nueva creación (dependiente del Ministerio de Educación, Cultura y Deporte), entre cuyos fines se encuentra recuperar, conservar y poner a disposición de los ciudadanos documentos para el estudio de la Guerra Civil, la dictadura franquista y la Transición ${ }^{6}$.

Fruto de este devenir histórico, el acervo documental que hoy conserva el Centro presenta orígenes muy dispares. Durante la etapa franquista, como ya hemos mencionado, la documentación fue incautada con propósito persecutorio o propagandístico a instituciones militares, políticas, sindicales y a particulares. En el periodo democrático, sin embargo, se han incorporado nuevos fondos merced a transferencias desde otros archivos (documentación de órganos represores) o mediante compra (modalidad de ingreso predominante en cuanto a colecciones fotográficas). Nuestro objetivo, en relación con este rico conjunto documental que se ha ido configurando, es facilitar una útil guía al investigador que desee

2 En abril de 1937 los nacionales crearon la Oficina de Investigación y Propaganda Anticomunista y al mes siguiente la Delegación de Asuntos Especiales, las dos dependientes del Cuartel General de Franco. A partir de la caída de Bilbao (junio de 1937) se pone en marcha el Servicio de Recuperación de Documentos, elevado a delegación del Estado en abril de 1938. Finalmente, en septiembre de 1944 se unificarán ambas en la Delegación de Servicios Documentales de la Presidencia del Gobierno (habitualmente denominada DNSD). Vid. Antonio GONZÁLEZ QUINTANA, Fuentes para el estudio de la represión franquista en el Archivo Histórico Nacional, Sección Guerra Civil, en Espacio, Tiempo y Forma. Historia Contemporánea, 7 (1994), pp. 480-503.

3 En mayo de 1979 pasa a depender del Ministerio de Cultura. Vid. María Teresa DíEz DE LOS Ríos San Juan, Estado actual de la Sección Guerra Civil del Archivo Histórico Nacional, en Studia Historica. Historia Contemporánea, 3 (1985), p 129.

4 Real Decreto 426/1999 de creación del Archivo General de la Guerra Civil Española, Boletín Oficial del Estado (BOE), 13/3/1999, pp. 10244-10246.

5 BOE, 18/11/2005, pp. 37723-37725.

6 Real Decreto 697/2007 por el que se crea el Centro Documental de la Memoria Histórica, BOE, 15/6/2007, p. 25976. 
adentrarse en la historia de la Iglesia española contemporánea. A tal fin pasaremos revista, desde una óptica cronológica y temática, a los principales fondos y colecciones que resultan de interés.

\section{LA IGLESIA DURANTE LA SEgUNDA REPÚBLICA}

Comenzando por el estudio de las difíciles relaciones entre la Iglesia Católica y la Segunda República (1931-1936), conserva nuestro Centro para su estudio tanto documentación textual como gráfica. La primera, que se concentra en el grupo de fondos Político-Social (en adelante PS)-Madrid, está representada por documentos de algunos partidos políticos de carácter confesional (es el caso de la Comunión Tradicionalista) y por documentación generada por medios de comunicación católicos. Particularmente interesante es el conjunto documental de la Escuela Periodística de El Debate. Tenida por la primera escuela de periodismo en España, fue creada por Ángel Herrera Oria en 1926 y pervivió hasta el estallido de la Guerra Civil. En ella se aplicaron innovadores métodos pedagógicos para dotar a los periodistas de un sólido bagaje cultural y religioso ${ }^{7}$. En este fondo se conservan solicitudes de ingreso para el curso 1935-1936, que acompañan exámenes y artículos ${ }^{8}$.

Respecto a la documentación gráfica, despunta un grupo de instantáneas que debemos al gran fotógrafo catalán Centelles. Agustí Centelles (1909-1984) comenzó a trabajar como fotoperiodista en 1927. A lo largo de su carrera profesional colaboró con medios como La Vanguardia, Publicitat, Diari de Barcelona o Última Hora (además de con agencias extranjeras), aunque ha pasado a la historia por las fotografías de los combates en las calles de Barcelona al inicio de la gue$\mathrm{rra}^{9}$. Las imágenes que ahora nos interesan reflejan la etapa anterior: la política republicana hacia las órdenes religiosas, el intento de conciliación que supuso la

7 Mercedes GORdón PÉREZ, La enseñanza del periodismo en el mundo occidental: estudio histórico y comparado de tres escuelas (tesis doctoral), Madrid, 1991, pp. 66, 68-70, 95-96 y 181-184.

8 Estos documentos se agrupan en la unidad de instalación PS-Madrid, 996. En esta misma sección (cajas 152 y 1536) se conserva documentación sobre los ataques a edificios religiosos durante la Primavera Trágica.

9 Durante el conflicto bélico estuvo vinculado al Comisariado de Propaganda de la Generalidad de Cataluña y al Departamento Especial de Información del Ministerio de la Gobernación. Además de la vida cotidiana en Barcelona, inmortalizó el frente de Aragón y las duras condiciones de vida de los refugiados españoles en el sur de Francia. Vid. VV. AA., Agusti Centelles (1909-1985), fotoperiodista, Barcelona, 1991, pp. 19-25. 
visita del cardenal Pacelli (septiembre de 1934), futuro papa Pío XII, y las más célebres de religiosos votando en las elecciones de febrero de 1936 (en total unas dieciséis imágenes, aproximadamente $)^{10}$.

\section{LA VIOLENCIA ANTIRRELIGIOSA EN EL PERIODO BÉLICO}

El largo final de la Segunda República comienza con la sublevación militar del 18 de julio de 1936. El fracasado golpe de Estado divide el país en dos y desemboca en una cruenta guerra civil (1936-1939). Durante el conflicto numerosos católicos serán perseguidos en la zona gubernamental como desafectos. Habida cuenta de la documentación conservada nos centraremos en la persecución republicana, si bien hubo católicos represaliados en la zona nacional por su lealtad al gobierno legítimo o su vinculación al nacionalismo vasco. Conviene advertir, sin embargo, que estos documentos contienen información que es abiertamente tendenciosa, ya que fueron generados con fines represivos y propagandísticos en el contexto de la victoria franquista.

Por orden cronológico debemos detenernos en primer lugar ante el Fichero de la Auditoría de Guerra del Ejército de Ocupación. La Auditoría se ocupaba de recabar datos sobre habitantes de las zonas que iba ocupando el Ejército Nacional con vistas a utilizar la información en los procesos militares que se abrieran contra ellos. De aquella labor persiste un «Fichero de Criminalidad»y unos libros índices. En el fichero, que fue creado entre 1937 y 1938, se reúnen algo más de quinientas treinta y cuatro mil fichas organizadas por provincias y localidades, aunque no todas llegaron a contar con fichero. Estas cédulas pueden dividirse en dos tipos: las que ofrecen información estadística o sumaria sobre cada una de las localidades (robos, saqueos e incendios; registros domiciliarios, detenciones, colectivizaciones, sedes de partidos, sindicatos y otras asociaciones; asesinatos, fusilamientos, peticiones de dinero e incendios) y las que contienen datos sobre personas.

La información obtenida se integró un poco más tarde, a partir de abril de 1940, en la Causa General, magna recopilación de los supuestos hechos delictivos cometidos bajo el Gobierno republicano desde las elecciones de febrero de 1936

10 Este archivo fotográfico dispone de una base de datos de uso interno que permite la búsqueda por título, fecha, soporte, etc. y actualmente ha comenzado su descripción en el Portal de Archivos Españoles (PARES). 
hasta el final de la Guerra Civil ${ }^{11}$. La Causa está compuesta por las piezas que produjo la instrucción y la documentación republicana recopilada como prueba. Las piezas se encuentran organizadas por provincias y dentro de estas, a su vez, de manera temática:

- Pieza principal o primera.

- Pieza segunda. Del alzamiento nacional.

- Pieza tercera. Cárceles y sacas.

- Pieza cuarta. Checas.

- Pieza quinta. Fusticia roja.

- Pieza sexta. Prensa roja.

- Pieza séptima. Actuación de las autoridades gubernativas locales.

- Pieza octava. Delitos contra la propiedad e informes de las cámaras oficiales de comercio e industria.

- Pieza novena. Banca.

- Pieza décima. Persecución religiosa.

- Pieza undécima. Tesoro artístico y cultura roja.

Hay que advertir, sin embargo, que en las provincias donde se impusieron los sublevados prácticamente desde el comienzo de la guerra solo llegó a instruirse la pieza principal o primera. Esta pieza contiene para la zona republicana relaciones de víctimas (represaliados por los republicanos), declaraciones de allegados y certificados de defunción, con presencia de numerosos eclesiásticos.

Para nuestro objeto de estudio también interesa la pieza tercera, concerniente a cárceles. En ella encontraremos informes sobre las prisiones (algunas instaladas provisionalmente en edificios de instituciones religiosas), relaciones de presos, internos «sacados» para ser asesinados y declaraciones de testigos. Similar documentación contiene la cuarta pieza, denominada «checas». Las checas eran centros ilegales de detención, en manos de partidos y sindicatos, que también utilizaban en ocasiones edificios eclesiásticos. Tanto a las prisiones como a las checas fueron a parar numerosos religiosos y católicos en general, por el mero hecho de serlo.

11 José Luis Ledesma, La «Causa General»: fuente sobre la «represión», la Guerra Civil (y el franquismo), en Spagna Contemporanea, 28 (2005), pp. 204-207; Carmen MAGÁN MERCHÁN, Isabel LÓPEZ ESCASO y Juan Magín MARTÍN ARNESTO, Causa General: la represión de «los más perversos ideales», en Cuartas fornadas Archivo y Memoria, Madrid, 2009, pp. 22-32. 
Circunscrita a la persecución religiosa se encuentra la pieza décima, que se compone de informes y relaciones de religiosos o seglares asesinados, así como de bienes destruidos. Tales documentos fueron elaborados por los diferentes obispados, aunque otras veces correspondió esta tarea a los ayuntamientos, a la Guardia Civil o a los fiscales. En ocasiones insertan fotografías de obras de arte sacro e, incluso, recortes de prensa y libros ${ }^{12}$.

La pieza undécima, por último, se consagra al tesoro artístico y a la educación. Los informes, ora sobre la destrucción del patrimonio cultural, ora sobre la situación de la enseñanza, son sus tipos documentales más representativos, redactados unos por la Comisaría del Servicio de Defensa del Patrimonio Artístico Nacional y otros por los directores de los establecimientos educativos. A veces se completan con fotografías de obras de arte sacro (en especial orfebrería), así como libros de la época acerca de la desaparición de este tipo de bienes $^{13}$.

En general, se advierte una cierta desproporción informativa entre provincias, incluso entre las que permanecieron toda la guerra bajo la misma bandera. El grupo de fondos completo está formado por cuatro mil unidades de instalación, con unas fechas que van de 1940 a $1967^{14}$.

Propósito muy diferente es el que encierran los documentos del Comité Internacional de la Cruz Roja, que reflejan la importante labor humanitaria de esta organización durante la guerra. En relación con el tema que nos ocupa debemos destacar la correspondencia de una colonia de las Juventudes Obreras Católicas refugiadas en Ávila entre noviembre de 1936 y junio de 1937 (dos expedientes) y las listas de religiosos residentes, detenidos o evacuados de las grandes ciudades republicanas: Madrid, Valencia y Barcelona (siete documentos) $)^{15}$.

La persecución religiosa fue utilizada como importante argumento contra la causa de la republica. Por ello hubo intentos desde algunos sectores, fundamentalmente el Partido Nacionalista Vasco, de contrarrestar la propaganda de los

12 Por ejemplo VV. AA., La persecución religiosa en la archidiócesis de Sevilla, Sevilla, 1938.

13 Vid. a título ilustrativo José HernáNDEZ Díaz y Antonio SANCHO CorbaCHO, Estudio de los edificios religiosos y objetos de culto de la ciudad de Sevilla, saqueados y destruidos por los marxistas, Sevilla, 1936; ID., Estudio de los edificios religiosos y objetos de culto saqueados y destruidos por los marxistas en los pueblos de la provincia de Sevilla, Sevilla, 1937.

14 Más información en PARES: <http://pares.mcu.es/ParesBusquedas/servlets/Control_servlet?accion=3\&txt_ id_desc_ud=2600914> [consultado 28/12/2015].

15 Puede consultarse presencialmente un inventario en francés, confeccionado por el propio Comité, en el que figura la signatura, el título y las fechas extremas. 
sublevados y movilizar a la opinión pública católica de otros países. Este esfuerzo ha quedado plasmado en informes y listados de personas e instituciones a los que enviar propaganda (1937), procedentes de la Delegación del Gobierno de Euskadi en Cataluña ${ }^{16}$.

\section{LA DOCUMENTACIÓN INCAUTADA Y SU DEVOLUCIÓN}

Otra consecuencia de la persecución religiosa fue la incautación de documentación de instituciones eclesiásticas, unas veces para ser utilizada en la propia represión, otras por la mera ocupación de los edificios de tales instituciones. La mayor parte de estos documentos se conservan en el grupo de fondos denominado «PS-Documentación Particular».

Predominan en él los fondos de entidades benéficas, Compañía de Jesús, conventos femeninos, juventudes católicas y colegios de enseñanza, ubicados en Madrid, Cataluña, Cantabria, Valencia y País Vasco. La mayor parte es documentación contable, seguida por correspondencia y relaciones de miembros, aunque no faltan manuscritos y relatos de sucesos. Destaca la Compañía de Jesús, con documentos del siglo XVII. En general, las fechas del conjunto van de dicha centuria al comienzo de la Guerra Civil. En una primera aproximación (a través del inventario existente), se han podido identificar treinta y tres instituciones productoras que se muestran en la tabla de la página siguiente.

Aparte de estos fondos, el investigador no debería pasar por alto los archivos nobiliarios de PS-Documentación Particular, que poseen documentos relacionados con la Iglesia, teniendo en cuenta el tradicional patronazgo que la aristocracia española ha ejercido sobre las instituciones eclesiásticas.

No obstante, buena parte de los archivos incautados durante el conflicto fueron devueltos en la Posguerra a sus titulares, en su mayoría colegios y conventos de Madrid, Cantabria, País Vasco y Cataluña. El proceso ha quedado plasmado en unos treinta y tres expedientes (1938-1958), que forman parte de la serie denominada $\ll$ DNSD-Correspondencia ${ }^{17}$.

\footnotetext{
16 Se conserva esta documentación en PS-Barcelona, 932.

17 Cuenta con un inventario topográfico consultable presencialmente.
} 
Tabla 1. Documentación eclesiástica en PS-Documentación Particular

\begin{tabular}{|c|c|}
\hline Institución/materia & Signatura \\
\hline Agustinas Recoletas Descalzas (Almansa, Albacete) & 6,3 \\
\hline Archidiócesis de Valencia & 19,1 \\
\hline Archivo Diocesano de Santander. Comisión de Capellanías & 714,3 \\
\hline Bernardas. Monasterio de Nuestra Señora del Río y San José (Santander, Cantabria) & 526 \\
\hline Carmelitas. Convento de San José (Barcelona) & 650 \\
\hline Casa Asilo de San José (Tarragona) & 705,1 \\
\hline Centro Católico (Torrelavega, Cantabria) & 526 \\
\hline Cofradía del Cordón (Reus, Tarragona) & 6,2 \\
\hline Compañía de María (Talavera de la Reina, Toledo) & $612-613$ \\
\hline Esclavas del Sagrado Corazón (Madrid) & 680 \\
\hline Escuela Dominical (Reinosa, Cantabria) & 672,3 \\
\hline Franciscanas. Convento de Santa María de Jesús (Reus, Tarragona) & 102,7 \\
\hline Hermanas de Nuestra Señora de la Consolación (Ametlla del Mar, Tarragona) & 49,2 \\
\hline Iglesia de Nuestra Señora de la Victoria (Barcelona) & 755 \\
\hline Jesuitas & 99,8 \\
\hline Jesuitas. Curia de la Provincia de Aragón & 690,1 \\
\hline Junta Provincial de Beneficencia (Valencia) & 678,6 \\
\hline Juventud Católica Española (Madrid) & 667,2 \\
\hline Juventud Católica Española (San Román de la Llanilla, Cantabria) & 12,1 \\
\hline Juventud de Acción Católica (Don Benito, Badajoz) & 532 \\
\hline Mínimos. Convento de la Victoria (Madrid) & 709,1 \\
\hline Padres de los Sagrados Corazones. Provincia Hispana & 662,1 \\
\hline Parroquia de Nuestra Señora de la Asunción (Albistur, Guipúzcoa) & 708,2 \\
\hline Parroquia de San Martín (Madrid). Asociación de Sagrados Viáticos & 704,2 \\
\hline Parroquia de Santa María (Gador, Almería) & 97,12 \\
\hline Parroquia de Yurre (Bizkaia) & 76,2 \\
\hline Real Montepío de San Pedro Pescador (Barcelona) & 678,4 \\
\hline Religiosas de María Inmaculada (Reus, Tarragona) & 535 \\
\hline Religiosas de María Inmaculada (Vicálvaro, Madrid) & 646 y 754 \\
\hline $\begin{array}{l}\text { Sindicato Agrícola de San Antonio de Padua (Renedo de Piélagos, Cantabria). } \\
\text { Caja de Ahorros y Préstamos }\end{array}$ & 526 \\
\hline $\begin{array}{l}\text { Terciarias Franciscanas de la Inmaculada Concepción. Convento de Santa María } \\
\text { Magdalena (Madrid) }\end{array}$ & 99,9 \\
\hline Virgen de Ezquioga & 650 \\
\hline
\end{tabular}




\section{LOS EFECTOS DEL CONFLICTO SOBRE EL PATRIMONIO}

Son probablemente las imágenes los documentos que mejor evidencian los efectos de la Guerra Civil sobre el patrimonio cultural. Las colecciones y archivos fotográficos que conserva el Centro Documental muestran, en toda su crudeza, las devastadoras consecuencias del conflicto sobre los bienes con interés cultural en manos eclesiásticas.

Un buen ejemplo es el llamado «Archivo Rojo», en puridad Archivo Fotográfico de la Junta Delegada de Defensa de Madrid. Contiene imágenes del periodo bélico, aunque también aparecen instantáneas anteriores procedentes del Patronato Nacional de Turismo (finales de los años veinte y etapa republicana). Cada fotografía se acompaña de su respectiva ficha de época, en la cual figura la localidad, el asunto representado y el autor. Veinticinco de ellas reflejan edificios religiosos de Madrid, destruidos por la artillería y los bombardeos aéreos: iglesias del Buen Suceso, San Luis y San Sebastián, además de los conventos de la Encarnación y del Corazón de María. Asimismo figura algún templo de la provincia de Guadalajara ${ }^{18}$.

Daños en los templos aparecen también en las fotografías de Albert Louis Deschamps (reportero gráfico de la revista L'Illustration) ${ }^{19}$, en este caso de Durango (Vizcaya) y Aragón, además de profanaciones en el cementerio de Huesca. Son alrededor de unas ochenta imágenes tomadas en $1938^{20}$.

Otro fotógrafo extranjero que trabajó en zona nacional fue Erich Andres. Las imágenes que conserva el Centro Documental recogen, entre otros aspectos, daños en imágenes religiosas y en la iglesia de Nuestra Señora del Juncal de Irún (Guipúzcoa) o en la iglesia de Santa María de los Alcázares de Maqueda (Toledo). Unas cuarenta imágenes aproximadamente, que el fotoperiodista alemán obtuvo entre septiembre y octubre de $1936^{21}$.

En el lado republicano tenemos a Kati Horna, fotógrafa de origen húngaro que colaboró con diversas revistas anarquistas como Libre Studio, Mujeres Libres, Tierra y Libertad, Tiempos Nuevos y Umbral. Tras la guerra se exiliará en México ${ }^{22}$.

18 Accesible en monográficos de PARES: <http://pares.mecd.es/ArchFotograficoDelegacionPropaganda/inicio.do $>$ [consultado 5/2015].

19 Marie Loup SougeZ, Albert-Louis Deschamps: fotógrafo en la Guerra Civil Española, Salamanca, 2003, pp. 13-24.

20 Más información sobre el archivo fotográfico en <http://pares.mcu.es/ParesBusquedas/servlets/ Control_servlet?accion=3\&txt_id_desc_ud=116997> [consultado 11/1/2016].

21 Más información en <http://pares.mcu.es/ParesBusquedas/servlets/Control_servlet?accion=3\&txt_ id_desc_ud=2621447> [consultado 14/1/2016].

22 VV. AA., Kati Horna: fotografías de la Guerra Civil Española (1937-1938), Salamanca, 1992, pp. 9-11. 
Una docena de las fotografías que tomó durante la contienda (1937) muestra la reutilización de edificios religiosos para usos civiles o militares (talleres, hospitales, comedores) en Barcelona y Aragón ${ }^{23}$.

Diversidad de origen hallaremos, por último, entre las tarjetas postales de la Colección Armero. El abogado y periodista José Mario Armero (1936-1995) fue un gran recopilador de documentos y objetos relacionados con la historia de España en la primera mitad del siglo XX. El grupo más voluminoso de las postales que nos interesan refleja los daños en el patrimonio religioso, sobre todo inmueble, por incendios, bombardeos y reutilización de las construcciones para otros usos durante el conflicto fratricida ${ }^{24}$. Aparecen edificios dañados de Barcelona, Oviedo, Bujalance (Córdoba), Lora del Río (Sevilla), Motril y Loja (Granada), entre otras poblaciones andaluzas. La mayoría pertenece a la colección Los horrores del marxismo, publicada en Sevilla en 1937. El conjunto de documentos que representan edificios religiosos, y también alguna ceremonia, está compuesto por setenta y siete piezas ${ }^{25}$.

\section{LA IGLESIA DURANTE EL FRANQUISMO}

El apoyo de la Iglesia al bando nacional se encuentra muy bien plasmado en el archivo fotográfico de Erich Andres, que mencionábamos más arriba. Acontecimientos como la presencia del arzobispo de Valladolid, Remigio Gandasegui, en el Te Deum por la conquista de San Sebastián, la cesión del palacio episcopal de Salamanca al general Franco y el aprovechamiento de edificios religiosos como acuartelamiento de tropas o refugio están plasmados en los clichés de este reportero. Además, entre las ciento setenta imágenes que abordan la temática que nos interesa, aparecen imágenes de una visita a las reliquias teresianas del Monasterio de la Anunciación de Alba de Tormes (Salamanca) y a las catedrales de Burgos, Zamora, Salamanca, Ávila y Sevilla.

El también referido Deschamps se detiene en destacados santuarios españoles como El Pilar y Santa Engracia en Zaragoza o la Sagrada Familia de

23 Archivo fotográfico disponible en <http://pares.mcu.es/ParesBusquedas/servlets/Control_ servlet? accion=3\&txt_id_desc_ud=116999> [consultado 6/5/2016].

24 Igualmente contiene un conjunto de treinta postales acerca de la destrucción de edificios religiosos en Barcelona durante la Semana Trágica (1909).

25 La colección cuenta con una base de datos de uso interno en la que aparece el autor, el título, la signatura y una breve descripción de cada tarjeta postal. Los técnicos del Centro pueden llevar a cabo búsquedas en las herramientas de uso interno a demanda de los investigadores. 
Barcelona. Pero sobre todo a través de sus fotografías nos podemos acercar a la práctica religiosa en la zona nacional durante la guerra (1939): procesiones, mujeres rezando y ataviadas con mantilla, sacerdotes, etc., hasta llegar a un volumen cercano a las setenta imágenes (incluyendo los monumentos).

Si repasamos, en cambio, la documentación textual, debemos comenzar por la documentación que generó la propia Secretaría de la DNSD. En esta documentación el apoyo recíproco adopta, por un lado, la forma de cesión de diferentes edificios de la ciudad de Salamanca como sede de los servicios de recuperación de documentos (universidad pontificia, noviciado de los jesuitas, colegio de San Ambrosio y convento de San Esteban $)^{26}$; y por otro las gestiones de diversas instituciones eclesiásticas ante la Delegación para recuperar sus bienes (unas veces los mismos documentos, otras buscando pruebas de su incautación) o para investigar las vicisitudes de los religiosos.

Un aspecto muy interesante de este periodo es la relación entre la masonería y la Iglesia, concretamente la conducta religiosa de los antiguos masones y la intervención eclesiástica en sus abjuraciones. La documentación del Tribunal Especial para la Represión de la Masonería y el Comunismo da pie al estudio de tales comportamientos ${ }^{27}$. Este tribunal se creó en 1940 con el fin de castigar a los partidarios de «ideas disolventes» contra la religión, la patria y la «armonía social». Así pues, estos enemigos del orden constituido eran tanto los masones como los comunistas, concepto bajo los cuales se englobaba un amplio espectro de personas de ideas republicanas o de izquierdas. El franquismo mantuvo está jurisdicción represiva hasta 1963, cuando será sustituida por el Tribunal de Orden Público ${ }^{28}$.

El mismo año en que se crea el Tribunal Especial (1940), la Delegación de Educación Popular de Barcelona de Falange comenzó a editar La Frase Quincenal, un conjunto de carteles que contienen consignas y motivos gráficos alusivos. Actualmente el Centro Documental conserva ochenta y cuatro documentos que nos ilustran sobre los rasgos ideológicos básicos de franquismo y los cambios que experimentó la propaganda a raíz de la evolución internacional ${ }^{29}$. Seis de ellos po-

26 Son cuatro expedientes, con fechas que van de 1937 a 1957 , que pueden encontrarse en DNSDSecretaría, exp. 970/2-5. Puede consultarse, presencialmente, un rudimentario inventario alfabético realizado a partir de un antiguo fichero.

27 La recuperación de los procesos se realiza de manera onomástica a través de un fichero digitalizado. En el momento de redactar estas líneas ya pueden encontrarse los nombres en PARES, aunque todavía no tienen asociadas las imágenes de las fichas.

28 Guillermo PORTILLA, La consagración del Derecho Penal de autor durante el Franquismo: el Tribunal Especial para la Represión de la Masonería y el Comunismo, Granada, 2009, pp. 39-46 y 64-70.

29 En breve la colección estará descrita en PARES, junto con las imágenes de los documentos. 
nen de manifiesto la utilización de la religión como argumento: sentido católico del régimen y recordatorio de la persecución religiosa durante la Guerra Civil, definida como cruzada. Precisamente tales piezas son las más ricas iconográficamente de todo el fondo, con representaciones de la catedral de Burgos, una cruz de término, los evangelios y un templo en llamas. Estos carteles obedecen a los cambios que experimenta el régimen tras la Segunda Guerra Mundial, buscando distanciarse de las potencias fascistas (1945-1948). A nivel interno supuso la pérdida de influencia de los falangistas a favor de los católicos ${ }^{30}$.

La propia Jefatura del Estado (Secretaría Particular) generó un variado conjunto documental que facilita una aproximación al papel de la Iglesia en la etapa franquista. Por medio de algunos de los más de veintisiete mil documentos que componen este fondo podemos acercarnos, primero, a la importancia de las relaciones con la Santa Sede y con el importante lobby católico americano durante los últimos cuarenta y principios de los cincuenta, con vistas a romper el bloqueo a España $^{31}$. Y más tarde verificar el cambio experimentado durante los años sesenta y setenta, con el apoyo del sector más aperturista de la Iglesia a movimientos políticos y sindicales en defensa de la democracia. Otros documentos, por el contrario, informan de cómo el régimen utilizó propagandísticamente la persecución a los católicos en los países comunistas; sobre la postura de España a favor de la internacionalización de los santos lugares o acerca del Concilio Vaticano Segundo, el Opus Dei y la masonería ${ }^{32}$.

\section{LA TRANSICIÓN ESPAÑOLA A LA DEMOCRACIA}

Durante los años crepusculares del Franquismo, la Jurisdicción de Orden Público (1963-1977) se encargó de perseguir los actos destinados a subvertir los principios básicos del régimen ${ }^{33}$. Como queda demostrado en algunos de los procesos que conforman este grupo de fondos (constituido en su totalidad por dos mil cuatrocientas sesenta y nueva cajas), los sectores aperturistas de la Iglesia

30 José Luis Hernández Luis, La «Frase Quincenal» en el Centro Documental de la Memoria Histórica, en Segle XX. Revista Catalana d'Historia, 10 (2017).

31 Esta información se puede ampliar con los documentos del Archivo del Ministerio de Asuntos Exteriores.

32 Dispone de un inventario topográfico, completado con unos índices de instituciones, lugares, materias y nombres, que puede consultarse presencialmente.

33 Juan José DEL ÁGUILA, El TOP: la represión de la libertad (1963-1977), Barcelona, 2001, pp. 227 255 y $345-351$. 
respaldaron a los grupos antifranquistas. También aparece en los procesos la represión de que fue objeto el clero vasco de tendencia nacionalista ${ }^{34}$.

Fallecido el dictador, se dio paso a una etapa de grandes cambios y expectativas. En la sociedad española afloraron multitud de colectivos de todo tipo, cuyas actividades han quedado reflejadas en la colección de pegatinas que Fernando Íñigo Aristu vendió al Ministerio de Cultura en 2009. Por lo que respecta al ámbito católico, son movimientos de carácter fundamentalista los representados: ambos sectores carlistas y la organización denominada «Movimiento Católico Español» ${ }^{35}$. Un total de diez y ocho piezas insertas en una colección que abarca el lapso 1975-1982.

Otro colectivo importante en la Transición fue el feminista, representado en nuestro acervo por la documentación acumulada por el Centro de Investigación y Formación Feminista (CIFFE). Esta entidad nació en 1983, aunque su origen arranca de la actividad de diversas asociaciones de amas de casa madrileñas en la década de los setenta. Entre sus documentos se conservan revistas que reflejan la relación con grupos cristianos: Comunidades Cristianas Populares, así como Hechos y Dichos: Revista de Pensamiento y Actualidad Cristiana, dirigida por Ignacio Elizalde Armendariz. Al igual que tres folletos acerca de temas polémicos como el divorcio, el aborto o la enseñanza en manos eclesiásticas, que fueron promovidos entre 1976 y 1977 por el Movimiento Familiar Cristiano. El conjunto documental incluye un expediente relativo a la denuncia por parte de organizaciones no gubernamentales, entre las que se encontraba la Federación de Asociaciones de Mujeres Flora Tristán, respecto de la financiación de la Iglesia Católica y sus repercusiones en el sistema de ayudas a las organizaciones sociales (1992 y 1994) ${ }^{36}$.

\section{LA BIBLIOTECA: ANTICLERICALISMO, DOCTRINA SOCIAL Y MASONERÍA}

El Centro Documental de la Memoria Histórica conserva una completa biblioteca, compuesta fundamentalmente por monografías, folletos y publicaciones seriadas. La colección se divide en dos grandes conjuntos: una parte histórica ge-

34 Existe una base de datos interna que permite la búsqueda geográfica, onomástica y por tipo de delito.

35 A los primeros los encontraremos en Incorporados, 1602, 982-993 y a los segundos en Incorporados, 1599, 372-377.

36 Existe una descripción básica del fondo en PARES: <http://pares.mcu.es/ParesBusquedas/servlets/ Control_servlet?accion=3\&txt_id_desc_ud=2622567> [consultado 02/11/2016], que puede completarse para los materiales especiales (carteles, casetes, vídeos, fotografías, pegatinas, etc.) con un inventario convencional disponible en la sala de usuarios. 
nerada por la incautación durante la Guerra Civil, y en menor medida por compras o donaciones recientes de materiales antiguos, y otra «moderna» con libros y revistas actuales (posteriores a la Transición) ${ }^{37}$. Para lo que a nuestro objeto de estudio concierne, vamos a reparar en las obras anticlericales, los trabajos acerca de la doctrina social de la Iglesia y los estudios sobre masonería y catolicismo.

Desde la óptica anticlerical destacan notablemente en el fondo antiguo las obras de varios autores, así españoles (Eduardo Barriobero, Joaquín Bartrina, Alfonso Martínez Carrasco, Emilio Gante, Manuel Puelo, Matías Usero y muy especialmente el periodista satírico José Nakens), como extranjeros (Otto von Corvin, Han Ryner o Charles Marcault). Entre las colecciones sobresalen El romancero anticlerical, con sonetos y romances compuestos por varios autores, y los folletos del Apostolado de la verdad. A modo de curiosidad cabe reseñar el libro que se intitula Anticlericalismo del Quijote, que dio a la estampa Simón Cerrejón en Madrid con ocasión del tercer centenario de la muerte de Cervantes. Como publicación periódica disponemos del Fray Lazo: Semanario Anticlerical Cortesmente Desvergonzado, del que se conservan veinte números aparecidos entre 1931 y 1932.

Otro ámbito temático muy presente en la biblioteca es el de la doctrina social de la Iglesia, con tratadistas como el teólogo francés Louis Garriguet ( $E l$ Trabajo) o el político italiano Francesco Saverio Nitti (El socialismo católico). Entre los autores españoles encontraremos a Emilio Azarola (Errores económicos en la encíclica Rerum Novarum), Ernesto Guitart (La Iglesia y el obrero) y el agustino Teodoro Rodríguez (La liberación del obrero). Asimismo, conservamos sendos ejemplares de las Semaines Sociales de France (undécima y duodécima), publicados en París a comienzos de los años veinte.

Probablemente la relación entre masonería e Iglesia sea el tema mejor representado. En el fondo histórico la teósofa rusa Blavatsky (Los orígenes del ritual en la Iglesia y en la masonería), el obispo francés Heri Delassus (La conjuration antichreétienne), el ocultista danés Max Heindel (La masonería y el catolicismo) o el masón francés Leo Taxil (El Vaticano y los masones) son las plumas foráneas más acreditadas. Mientras que la producción nacional se encuentra representada por el teólogo riojano Niceto Alonso Perujo (El Papa y las logias) y Luis Villalba Muñoz (La masonería ante la Iglesia y la patria), amén de otros muchos.

37 Más detalles sobre el origen de la colección en María José TuRRIÓN GARCÍA, La Biblioteca de la Sección Guerra Civil del Archivo Histórico Nacional (Salamanca), en Boletín de la ANABAD, 47 (1997/2), pp. 96-105. 
Entre los estudiosos actuales, José Antonio Ferrer Benimelli, sacerdote jesuita, se ha ocupado en numerosos estudios de la relación entre la Iglesia Católica y la masonería: Masonería, Iglesia e Ilustración; La masonería y la Iglesia en el siglo XIX español; La masonería después del Concilio o Masonería e Iglesia en España. Todas estas obras se encuentran a disposición de los usuarios en la Biblioteca del Centro Documental.

Este apresurado repaso a los materiales bibliográficos no estaría completo sin las publicaciones periódicas. Para la historia de la Iglesia sobresale en nuestra colección La Semana Católica, con ejemplares que van de junio de 1912 al mes de agosto de 1934, aunque, lamentablemente, la serie no está completa ${ }^{38}$.

\section{BALANCE}

Como hemos podido constatar, para la historia de la Iglesia Católica los temas mejor representados en la documentación del Centro Documental de la $\mathrm{Me}$ moria Histórica son la violencia antirreligiosa durante la Guerra Civil Española (1936-1939) y los efectos del conflicto sobre el patrimonio cultural en manos eclesiásticas, ya sea arquitectónico, documental o de bienes muebles. Destacan sobremanera para esta línea de investigación cultural los importantes archivos fotográficos conservados.

Especialmente desconocidos son, sin embargo, los archivos incautados a instituciones religiosas, que se conservan de manera fragmentaria. En ellos es posible encontrar materiales insospechados, tanto por su naturaleza como por su antigüedad, en un archivo nacido con fines represivos durante el periodo franquista.

En lo que atañe a los materiales bibliográficos, que no deberían pasar desapercibidos para los estudiosos, descuellan para el tema que nos ocupa las obras de controversia relacionadas con el anticlericalismo, el sindicalismo católico y la relación entre la Iglesia y la masonería.

Una documentación, en suma, escasamente utilizada para la historia de la Iglesia, que hemos pretendido poner a disposición de los investigadores por medio de este trabajo.

38 Para más detalles sobre estos autores y obras remitimos al Catálogo de la Biblioteca: <www.mcu.es/ ccbae/es/inicio/inicio.cmd> [consultado 8/4/2016]. 
